\title{
Emergency Department High Utilizers among Family Medicine Patients
}

\author{
Stacey Kirkpatrick, BA, Denny Fe G. Agana, MPH, PhD, Kim Lynch, MSHI, and \\ Peter J. Carek, MD, MS
}

Background: Increases in emergency department (ED) use are contributing to inefficient health care spending and becoming a public health concern. Previous studies have identified characteristics of ED high utilizers aimed at designing interventions to improve efficiency. We aim to expand on these findings in a family medicine outpatient population.

Methods: We conducted a retrospective analysis on a population of ED high utilizers, defined as those who had been to the ED 6 or more times in 1 year, including medical and demographic characteristics from 2015 to 2017.

Results: Compared with our source population, ED high utilizers were most commonly female, African American, or single and insured by Medicare or Medicaid. They did not have a chronic pain or substance use diagnosis, but more than half had a psychiatric condition. The only demographic characteristic that changed over time was home location from 2015 to $2017(P<.05)$. Less than 10\% of ED high utilizers were the same over 3 years.

Conclusions: Most demographic characteristics did not change over time, whereas individuals did change. Interventions aimed at improving efficiency of ED use should be geared toward unchanging characteristics rather than individuals. The only demographic characteristic that did change significantly was home location that correlated in time with the availability of new EDs providing support for a theory of supply-sensitive ED use. (J Am Board Fam Med 2019;32:264-268.)

Keywords: Delivery of Health Care, Demography, Emergency Departments, Medicaid, Medicare, Outpatients, Primary Health Care, Public Health

High levels of emergency department (ED) use in the United States is contributing to increases in health care costs and is becoming a public health and safety concern due to overcrowding and more medical errors. ${ }^{1}$ Between 1993 and 2003, the number of ED visits rose from 90.3 million to 133.9 million. $^{2}$ Although these increases may be leveling off to a historic maximum, expenditures continue to rise. ${ }^{4} \mathrm{ED}$ care accounts for as much as $10 \%$ of health care spending and has been estimated at $\$ 38$

This article was externally peer reviewed.

Submitted 29 June 2018; revised 26 November 2018; accepted 28 November 2018.

From University of Florida College of Medicine, Gainesville, FL (SK); Department of Community Health and Family Medicine ((DFGA, KL, PC), Department of Epidemiology (DFGA), University of Florida, Gainesville.

Funding: none.

Conflict of interest: none declared.

Corresponding author: Stacey Kirkpatrick, BA, University of Florida College of Medicine, Gainesville, FL 32610 (Email: slk.kirkpatrick@gmail.com). billion per year in spending. ${ }^{3}$ In a nationwide study in 2009, patients without private insurance, including Medicare, Medicaid, and uninsured patients, were admitted to the ED at a substantial negative profit margin of up to $54 \%$. $^{4}$

Individuals who frequently visit the ED constitute $4 \%$ to $9 \%$ of all patients, but they account for $21 \%$ to $28 \%$ of ED visits. ${ }^{6,7}$ A study of nonelderly Medicaid patients showed that high utilizers made up a third of ED visits. ${ }^{8}$ ED high utilizers seem to visit the $\mathrm{ED}$ for a specific and limited period of time, suggesting that interventions aimed at these individuals once they have been identified based on their use would not be beneficial. ${ }^{6}$ Alternatively, interventions directed toward improving the care for patients with specific demographic characteristics or medical conditions may be a better strategy for reducing ED use due to specific barriers to health care such as lack of access to primary care. 
The specific characteristics of these patients that are most associated with ED have not been clearly and consistently delineated. Several studies have noted that various medical conditions comprise ED high utilizers and include patients with psychiatric and substance use disorders as well as chronic pain conditions. In a study of patients who were recently discharged from the hospital, psychiatric conditions alone accounted for $21 \%$ of ED visits. ${ }^{9}$ Another national retrospective study found that $20 \%$ of visits were for symptoms of nonmalignant chronic pain, ${ }^{10}$ making these diagnoses some of the most important in understanding ED use. Elderly patients visit the ED at higher rates and are more likely to arrive by ambulance, contributing to greater costs. ${ }^{11}$ Finally, insurance status has been noted to be associated with ED use. Between 2004 and 2011, the number of ED visits among uninsured patients increased and Medicaid patients in particular were twice as likely to visit the ED between 2004 and 2011. ${ }^{12}$ Lack of access to primary care and convenience has also been noted to impact ED use. ${ }^{13}$

As noted, the specific characteristics associated with patients felt to be high utilizers of the ED require further study and clarification. The study of these characteristics in active patients of a family medicine practice may assist these practices as they seek to reduce ED use in their patient populations. Therefore, the specific aim of this study was to examine the characteristics of patients who frequently visit the ED. In addition, we examined whether these characteristics change over a 3 -year period of time.

\section{Methods}

Patient data were obtained from the electronic medical record for patients who were at least 18 years old and have a family medicine physician within a network of 6 outpatient clinics located throughout 2 adjoining counties. ED high utilizers were patients that visited the ED at least 6 times in 1 calendar year (2015, 2016, and 2017). Although a wide range of definitions exist for a high utilizer of the ED, $6 \mathrm{ED}$ visits per year is commonly used in studies. ${ }^{14} \mathrm{We}$ considered all other patients low utilizers.

We included demographic characteristics, including age, sex, race, ethnicity, home address zip code, marital status, and insurance status. In addition, we identified trends in medical characteristics, including the presence of psychiatric conditions (e.g., depression, anxiety, bipolar disorder, and schizophrenia), substance use or chronic pain diagnoses, and number of medications.

We characterized each population by using descriptive statistics. We conducted additional analyses by using the unpaired $t$ test for continuous variables and $\chi^{2}$ test for categorical variables.

This study was approved by the University of Florida Institutional Review Board.

\section{Results}

The low utilizer population consisted of 18,368 patients from 2015 to 2017 , whereas the high utilizer population consisted of 943 patients. These 2 populations differed in average age as well as the proportion by sex, race, home location, marital status, insurance status, presence of chronic pain diagnosis, substance, psychiatric diagnosis, and number of medications (Table 1). Notably, the high utilizers had higher proportions of women and African Americans from the east side of our community. They were more often single with Medicaid or Medicare insurance. They were more likely to have a chronic pain, substance, and psychiatric condition and, on average, were prescribed more medications (Table 1).

The population of ED high utilizers consisted of 432 patients in 2015, 428 patients in 2016, and 427 patients in 2017 (Table 2). The high utilizers were most commonly either female, African American, or single. Medicare or Medicaid was the most common insurance and the population was largely nonHispanic. The majority of ED high utilizers did not have a chronic pain or substance use diagnosis, whereas more than half had a psychiatric condition.

There were no significant differences in any demographic characteristics when we compared 2015 to 2016, 2016 to 2017, or 2015 to 2017 ( $P$ > .05 ; Table 2). Home location for patients changed significantly from 2015 to $2017(P<.05)$ as more west side patients became high utilizers and fewer east side patients were noted. No differences were noted for the presence of chronic pain, substance abuse, or psychiatric conditions in patients when individual years were compared. Finally, $9.1 \%$ of the specific patients in the high utilizer group were the same across all 3 years (Figure 1).

\section{Conclusions}

The results indicate that patients who frequently use the ED have specific characteristics in the set- 
Table 1. Demographic and Medical Characteristics of Emergency Department High Utilizers from 2015 to 2017 Compared to General Family Medicine Outpatient Population of Low Utilizers

\begin{tabular}{|c|c|c|c|}
\hline Demographic or Characteristic & Low $<6 /$ yr & High $\geq 6 / y r$ & $P$ value \\
\hline Patients, n & 18,638 & 943 & \\
\hline Age, mean $( \pm S D)$ & $43.7( \pm 21.2)$ & $46( \pm 19.4)$ & $<.005^{*}$ \\
\hline \multicolumn{4}{|l|}{ Sex, n (\%) } \\
\hline Male & $7,154(38.4)$ & $313(33.2)$ & \multirow[t]{2}{*}{.002} \\
\hline Female & $11,484(61.6)$ & $630(66.8)$ & \\
\hline \multicolumn{4}{|l|}{ Race, n (\%) } \\
\hline White & $10,215(54.8)$ & $402(42.6)$ & \multirow[t]{3}{*}{$<.001^{* *}$} \\
\hline Black & $7,121(38.2)$ & $509(54.0)$ & \\
\hline Other & $1,141(6.1)$ & $32(3.4)$ & \\
\hline \multicolumn{4}{|l|}{ Ethnicity, n (\%) } \\
\hline Hispanic & $828(4.4)$ & $35(3.7)$ & \multirow[t]{2}{*}{.11} \\
\hline Non-Hispanic & $17,806(95.5)$ & $908(96.3)$ & \\
\hline \multicolumn{4}{|l|}{ Gainesville location, n (\%) } \\
\hline East & $5,808(31.1)$ & $409(43.3)$ & \multirow[t]{3}{*}{$<.001^{\text {** }}$} \\
\hline West & $6,030(32.2)$ & $250(26.5)$ & \\
\hline Other & $6,800(36.5)$ & $284(30.1)$ & \\
\hline \multicolumn{4}{|l|}{ Marital status, n (\%) } \\
\hline Single & $9,594(51.5)$ & $507(53.8)$ & \multirow[t]{4}{*}{$<.001^{\text {** }}$} \\
\hline Married & $6,371(34.1)$ & $229(24.2)$ & \\
\hline Divorced & $1,310(7.0)$ & $118(12.5)$ & \\
\hline Other & $1,154(6.2)$ & $89(9.4)$ & \\
\hline \multicolumn{4}{|l|}{ Insurance status, n (\%) } \\
\hline Commercial/third party & $8,342(44.8)$ & $215(22.8)$ & \multirow[t]{4}{*}{$<.001^{\text {** }}$} \\
\hline Medicare & $4,396(23.6)$ & $296(31.4)$ & \\
\hline Medicaid & $4,466(24.0)$ & $382(40.5)$ & \\
\hline Other & $1,431(44.8)$ & $50(22.8)$ & \\
\hline \multicolumn{4}{|l|}{ Chronic pain, $\mathrm{n}(\%)$} \\
\hline Yes, & $1,110(0.06)$ & $155(0.16)$ & \multirow[t]{2}{*}{$<.001^{\text {** }}$} \\
\hline No & $17,528(0.94)$ & $788(0.84)$ & \\
\hline \multicolumn{4}{|l|}{ Substance use, n (\%) } \\
\hline Yes & $1,648(0.09)$ & $210(0.22)$ & \multirow[t]{2}{*}{$<.001^{\text {** }}$} \\
\hline No & $16,990(0.91)$ & $733(0.78)$ & \\
\hline \multicolumn{4}{|l|}{ Psychiatric condition, n (\%) } \\
\hline Yes & $7,688(0.41)$ & $613(0.65)$ & \multirow[t]{2}{*}{$<.001^{\text {** }}$} \\
\hline No & $10,950(0.59)$ & $330(0.35)$ & \\
\hline Medications, mean $( \pm \mathrm{SE})$ & $7.4( \pm 0.06)$ & $25.45( \pm 0.66)$ & $<.001^{* *}$ \\
\hline
\end{tabular}

${ }^{*} P<.05,{ }^{* *} P<.001$.

$\mathrm{SD}$, standard deviation; SE, standard error.

ting of this family medicine population over this time period. These characteristics include middle age, African American, non-Hispanic, and single. Most ED high utilizers were insured by Medicaid and Medicare. In addition, most patients did not have a chronic pain or substance use diagnosis, but over $50 \%$ had a psychiatric condition.

Of note, only $9.1 \%$ of these patients were the same each year, whereas all demographic and medical characteristics, except home location, did not change over time. This finding suggests that the majority of patients who make up this high-utilizer population change over time, whereas their characteristics do not. As such, interventions aimed at improving efficiency of care for individual patients may be ineffective and the use demographic and medical characteristics of ED high utilizers in such activities may be more productive.

We noted a significant change in the pattern of home location for high utilizers. We hypothesize 
Table 2. Demographic and Medical Characteristics of Emergency Department High Utilizers from 2015 to 2017

\begin{tabular}{|c|c|c|c|c|c|c|}
\hline Demographic or Characteristic & 2015 & 2016 & 2017 & $\begin{array}{c}2015 \text { vs } \\
2016\end{array}$ & $\begin{array}{c}P \text { value } \\
2016 \text { vs } \\
2017\end{array}$ & $\begin{array}{c}2015 \text { vs } \\
2017\end{array}$ \\
\hline Patients, n & 432 & 428 & 427 & & & \\
\hline Age, mean $( \pm S D)$ & $46.2( \pm 18.5)$ & $45.8( \pm 18.2)$ & $46.1( \pm 18.8)$ & .78 & .84 & .94 \\
\hline \multicolumn{7}{|l|}{ Sex, n (\%) } \\
\hline Male & $150(34.7)$ & $142(33.2)$ & $134(31.4)$ & .66 & .61 & .31 \\
\hline Female & $282(65.30)$ & $286(66.8)$ & $293(68.6)$ & & & \\
\hline \multicolumn{7}{|l|}{ Race, n (\%) } \\
\hline White & $181(41.9)$ & $185(43.2)$ & $165(38.6)$ & .82 & .38 & .59 \\
\hline African American & $238(55.1)$ & $228(53.3)$ & $247(57.8)$ & & & \\
\hline Other & $13(3.0)$ & $15(3.5)$ & $15(3.5)$ & & & \\
\hline \multicolumn{7}{|l|}{ Ethnicity, n (\%) } \\
\hline Hispanic & $13(3.0)$ & $13(3.0)$ & $18(4.2)$ & 1 & .37 & .37 \\
\hline Non-Hispanic & $419(97.0)$ & $415(97.0)$ & $409(95.8)$ & & & \\
\hline \multicolumn{7}{|l|}{ Home location, n (\%) } \\
\hline East & $209(48.4)$ & $187(43.7)$ & $167(39.1)$ & .36 & .13 & $.014^{*}$ \\
\hline West & $94(21.8)$ & $97(22.7)$ & $122(28.6)$ & & & \\
\hline Other & $129(29.9)$ & $144(33.6)$ & $138(32.3)$ & & & \\
\hline \multicolumn{7}{|l|}{ Marital status, n (\%) } \\
\hline Single & $231(53.5)$ & $227(53.0)$ & $227(53.2)$ & .68 & .96 & .76 \\
\hline Married & $95(22.0)$ & $107(25.0)$ & $105(24.6)$ & & & \\
\hline Divorced & $62(14.4)$ & $53(12.4)$ & $57(13.3)$ & & & \\
\hline Other & $44(10.2)$ & $41(9.6)$ & $38(8.9)$ & & & \\
\hline \multicolumn{7}{|l|}{ Insurance status, n (\%) } \\
\hline Commercial/third party & $85(19.7)$ & $86(20.0)$ & $85(19.9)$ & .87 & .6 & .39 \\
\hline Medicare & $144(33.3)$ & $133(31.1)$ & $140(32.8)$ & & & \\
\hline Medicaid & $178(41.2)$ & $186(43.5)$ & $184(43.1)$ & & & \\
\hline Other & $25(5.8)$ & $23(5.4)$ & $18(4.2)$ & & & \\
\hline \multicolumn{7}{|l|}{ Chronic pain, n (\%) } \\
\hline Yes & $58(13.4)$ & $75(17.5)$ & $64(15.0)$ & .11 & .35 & .56 \\
\hline No & $374(86.6)$ & $353(82.5)$ & $363(85.0)$ & & & \\
\hline \multicolumn{7}{|l|}{ Substance use, n (\%) } \\
\hline Yes & $91(21.0)$ & $92(21.5)$ & $90(21.1)$ & .93 & .93 & 1 \\
\hline No & $341(78.9)$ & $336(78.5)$ & $337(78.9)$ & & & \\
\hline \multicolumn{7}{|l|}{ Psychiatric condition } \\
\hline Yes & $258(59.7)$ & $258(60.3)$ & 277 (64.9) & .18 & .89 & .12 \\
\hline No & $174(40.3)$ & $170(39.7)$ & $150(35.1)$ & & & \\
\hline Medications, mean $( \pm \mathrm{SD})$ & $48.8( \pm 33.5)$ & $51.0( \pm 34.8)$ & $50.9( \pm 34.3)$ & .35 & .97 & .36 \\
\hline
\end{tabular}

${ }^{*} P<.05$.

$\mathrm{SD}$, standard deviation.

that this finding is due to 2 new free-standing EDs on the west side of this community. These findings support the supply-sensitive use of emergency health care resources, similar to previous findings of use in multiple health care settings. ${ }^{15}$ More specifically, supply-sensitive care means that practice patterns are largely influenced by available resources. For example, Medicare enrollees in hospital service areas with more hospital beds per capita were more likely to be admitted regardless of so- cioeconomic status, and these increased rates were not associated with decreased mortality. ${ }^{16}$ Similarly, newborn intensive care unit bed supply was associated with increased admission rates for newborns with good health status. ${ }^{17,18}$ These findings extend into primary care where outpatient visits increase with increased physician supply even after accounting for sociodemographic differences. ${ }^{19}$ This may be extended to our finding that ED high utilizers from 1 geographical location in our com- 
Figure 1. Venn diagram of emergency department (ED) high utilizers by year, 2015 to 2017.

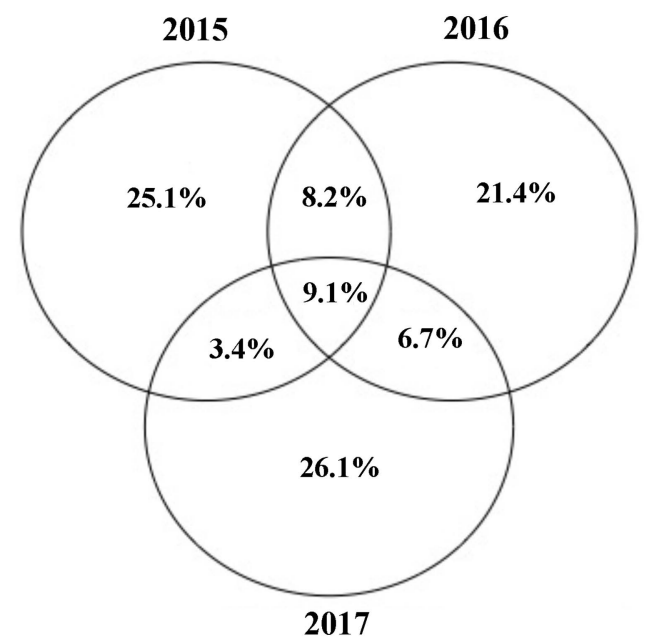

munity increased at the same time that more resources became available.

Several limitations of this study are present. The study included patient care data obtained retrospectively from a large academic health center hospital located in a southeastern US city. Therefore, the results and conclusions may not be applicable to other hospitals of varying types, size, or locations. In addition, the data used in this study were obtained from the hospital's administrative informational system and a mechanism to confirm accuracy was not available.

In conclusion, our study demonstrates an example of supply-sensitive care in ED use, even for patients with primary care physicians. It also provides evidence for aiming interventions toward demographic characteristics of ED high utilizers over individuals because of the unchanging nature of most of these characteristics.

To see this article online, please go to: http://jabfm.org/content/ 32/2/264.full.

\section{References}

1. Trzeciak S, Rivers E. Emergency department overcrowding in the United States: an emerging threat to patient safety and public health. Emerg Med J 2003; 20:402-5.

2. IOM Report: The future of emergency care in the United States health system. Washington, D.C.: National Academy of Sciences; 2006.

3. Lee M, Schuur J, Zink B. Owning the cost of emergency medicine: beyond 2\%. Ann Emerg Med 2013; $62: 498-505$.
4. Johansen ME. Comparing medical ecology, utilization, and expenditures between 1996-1997 and 2011-2012. Ann Fam Med 2017;15:313-21.

5. Wilson M, Cutler D. Emergency department profits are likely to continue as the affordable care act expands coverage. Health Aff (Millwood) 2014;33: 792-9.

6. Adams JG. Emergency department overuse: perceptions and solutions. JAMA 2013;309:1173-4.

7. LaCalle E, Rabin E. Frequent users of emergency departments: the myths, the data, and the policy implications. Ann Emerg Med 2010;56:42-8.

8. Capp R, Kelley L, Ellis P, et al. Reasons for frequent emergency department use by medicaid enrollees: a qualitative study. Acad Emerg Med 2016;23:476-81.

9. Vashi A, Fox J, Carr B, et al. Use of hospital-based acute care among patients recently discharged from the hospital. JAMA 2013;309:364-71.

10. Daubresse M, Hsien-Yen C, Yuping Y, et al. Ambulatory diagnosis and treatment of non-malignant pain in the United States, 2000-2010. Med Care 2013;51:870-8.

11. Aminzadeh F, Dalziel W. Older adults in the emergency department: a systematic review of patterns of use, adverse outcomes, and effectiveness of interventions. Ann Emerg Med 2002;39:238-47.

12. CDC. Health, United States, 2015: In Brief. Hyattsville, MD: National Center for Health Statistics; 2016

13. Uscher-Pines L, Pines J, Kellermann A, Gillen E, Mehrotra A. Deciding to visit the emergency department for non-urgent conditions: a systematic review of the literature. Am J Manag Care 2013;19:47-59.

14. Althaus F, Paroz., S., Hugli O, et al. Effectiveness of interventions at targeting frequent users of emergency departments: a systematic review. Ann Emerg Med 2001;58:41-52.

15. Wennberg J. Unwarranted variations in healthcare delivery: implications for academic medical centers. BMJ 2002;26:961-4.

16. Fisher E, Wennberg J, Stukel T, et al. Associations among hospital capacity, utilization, and mortality of U.S. Medicare beneficiaries, controlling for sociodemographic factors. Health Serv Res 2000;34:135162.

17. Freedman S. Capacity and utilization in health care: the effect of empty beds on neonatal intensive care admission. Am Econ J Econ Policy 2016;8:154-85.

18. Harrison W, Wasserman J, Goodman D. Regional variation in neonatal intensive care admissions and the relationship to bed supply. J Pediatr 2018;192: 73-9.

19. Yasaitis L, Bynum J, Skinner J. Association between physician supply, local practice norms, and outpatient visit rates. Med Care 2013;51:524-31. 